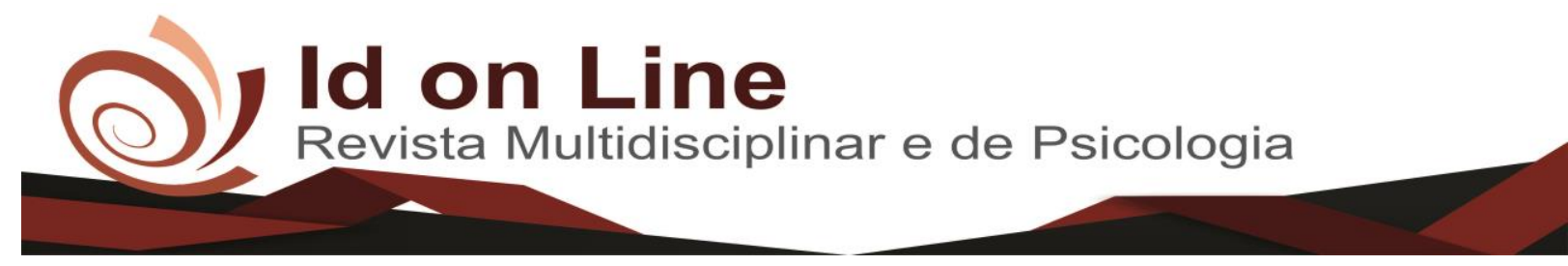

Artigo

\title{
Avaliação Contínua da Aprendizagem como Indicador da Qualidade Educacional
}

\author{
Ubaldo de Jesus Fonseca ${ }^{1}$; Mário Marcos Lopes ${ }^{2}$
}

\begin{abstract}
Resumo: O presente artigo tem como objetivo analisar a eficácia dos critérios da avaliação contínua da aprendizagem como indicador da qualidade educacional. Tomando como base um curso de graduação presencial em uma faculdade da rede pública estadual. O embasamento teórico envolveu autores como Luckesi (1995), Masetto (2003), Hoffmann (1999), Chueriri (2008), Pacheco (1995), Perrenoud (1999), Santos (2005), Stufflebeam (1987), assim como a Lei de Diretrizes e Base da Educação Nacional, o Projeto Político Pedagógico e o Regimento de uma faculdade pública. A pesquisa foi desenvolvida de forma exploratória e classificada como bibliográfica. Foi constatado nesse estudo entre outros resultados, que os atuais critérios de avaliações discentes são ineficazes, devendo os mesmos passarem por uma reestruturação. Contudo, propõe-se uma mudança drástica na cultura enraizada no Brasil, onde existe uma necessidade de quantificar o desempenho dos alunos em notas.
\end{abstract}

Palavras-Chave: Avaliação contínua; Graduação presencial; Rede pública estadual; Identificação e examinação; Investigação e dificuldades.

\section{Continuous Assessment of Learning as an Indicator of Educational Quality}

\begin{abstract}
This article aims to analyze the effectiveness of the criteria of the continuous assessment of learning as an indicator of educational quality. Based on a face-to-face undergraduate course at a state public school college. The theoretical foundation involved authors as Luckesi (1995), Masetto (2003), Hoffmann (1999), Chueriri (2008), Pacheco (1995), Perrenoud (1999), Santos (2005), Stufflebeam (1987) and the Law of Guidelines and Basis of National Education, the Political Pedagogical Project and the Regiment of a public faculty. The research was developed in an exploratory way and classified as bibliographical. It was found in this study among other results, that the current criteria of student evaluations are ineffective, and they must be restructured. However, it is proposed a drastic change in the culture rooted in Brazil, where there is a need to quantify students' performance in grades.
\end{abstract}

Keywords: Continuous evaluation; Undergraduate courses; State public network; Identification and examination; Research and difficulties.

\footnotetext{
${ }^{1}$ Administrador e Bacharel em Ciências Contábeis. Especialista em Docência no Ensino Superior pelo Centro Universitário Barão de Mauá - CUBM, Ribeirão Preto, São Paulo, Brasil. Especialista em Gestão Estratégica e Negócios pela Universidade do Estado da Bahia - UNEB, ubaldog12@yahoo.com.br, Santo Antônio de Jesus, Bahia, Brasil.

${ }^{2}$ Biólogo e Pedagogo. Mestre em Desenvolvimento Regional e Meio Ambiente pela Universidade de Araraquara - UNIARA. Docente da disciplina de Metodologia da Pesquisa Cientifica do Programa de Pós-Graduação em Docência no Ensino Superior do Centro Universitário Barão de Mauá - CUBM, Ribeirão Preto, São Paulo, Brasil.
}

124 Id on Line Rev. Mult. Psic. V.12, N. N. 41, p. p.124-138, 2018 - ISSN 1981-1179 Edição eletrônica em http://idonline.emnuvens.com.br/id 


\title{
Introdução
}

A avaliação está presente em todo o nosso cotidiano, portanto não existe apenas um tipo ou até mesmo consenso a cerca dos procedimentos que a envolvem. No âmbito escolar, a avaliação incide sobre as ações ou objetos específicos que são inerentes ao plano de ação e ao aproveitamento do aluno.

\begin{abstract}
A avaliação educacional, em geral, e a avaliação de aprendizagem escolar, em particular, são meios e não fins, em si mesmas, estando assim delimitadas pela teoria e pela prática que as circunstanciariam. Desse modo, entendemos que a avaliação não se dá nem se dará num vazio conceitual, mas sim dimensionada por um modelo teórico de mundo e de educação, traduzido em prática pedagógica (LUCKESI, 1995, p.28).
\end{abstract}

O exercício de avaliação da aprendizagem que vem sendo desenvolvido em nossas instituições de ensino públicas nos remete a uma posição de pouco avanço. Não tem sido utilizada como elemento que auxilia no processo ensino aprendizagem preocupando-se apenas em medir e quantificar o saber, deixando de identificar as potencialidades individuais e coletivas do educando. Tal procedimento só ocorrerá dentro do âmbito de uma avaliação contínua da aprendizagem.

A avaliação no contexto escolar para Chueriri (2008) constitui-se em prática intencional e organizada e se realiza a partir de objetivos pedagógicos claros e contextualizados.

O sistema de avaliação contínua vem sendo discutido por alguns autores, com o objetivo de compreender suas práticas e as dificuldades de sua aplicabilidade e continuidade. A avaliação não deve priorizar apenas o resultado ou o processo, mas a prática da investigação. A partir desse pressuposto, Luckesi (1995), sugere que a avaliação seja diagnóstica, ou seja, dados coletados deverão ser analisados criteriosamente, não com o objetivo de aprovar ou reprovar alunos, mas sim reverem o seu desenvolvimento, dando oportunidade para que ele avance no processo de construção do conhecimento em sua formação e construção social.

Os resultados escolares dos alunos é um dos campos mais problemáticos do sistema educativo, tornando-se face visível de um complexo edifício em permanente construção valorativa, através da recolha formal e informal de dados, com vista a uma tomada de decisão (PACHECO \& ZABALZA, 1995, p.17). 
A avaliação é fundamental para o bom funcionamento de qualquer disciplina (ninguém se preocupa com uma matéria que não vai ser avaliada), porém, não deve ser colada no centro de todas as preocupações, de forma finalista, numa prática minimalista e ambígua.

Atualmente conceitua-se como contexto das discussões já existentes entre autores através de vários artigos, monografias e projetos de pesquisa. Porém, apesar de todas estas discussões já existentes, os que subsidiam as práticas de avaliação nos ambientes acadêmicos parecem significá-las como perpétuas, intocáveis e distantes de qualquer possibilidade de ação reflexiva que traga transformações reais.

O presente projeto de pesquisa realizado com base em autores como Luckesi, Masetto, Hoffmann, Chueriri, Pacheco, Perrenoud, Santos, Stufflebeam, e outros, assim como Lei de Diretrizes e Base da Educação Nacional, o Projeto Político Pedagógico e o Regimento de uma faculdade pública, o mesmo pretende levantar dados e refletir sobre as dificuldades da transformação dos moldes tradicionais de avaliação para um modelo que considere a origem e o modo que o conhecimento é construído. Uma discussão a cerca da necessidade de implantação real desse processo que deve funcionar ao mesmo tempo de forma ampla e compatível com os objetivos estabelecidos pelas instituições acadêmicas de ensino e pelo professor dentro do seu planejamento estratégico e do seu Projeto Político Pedagógico (PPP).

Uma análise a cerca das dificuldades de implementação, junto a práticas que atendam mais adequadamente ao aluno em seu processo de construção do conhecimento, dos critérios de avaliação processual e contínua tão apregoada pelos professores em seus planos de curso.

As primícias desse processo, apesar de remontar aos primórdios da educação democrática são árduas. Remetendo ao desafio da mudança, as novas práticas de ensino determinam também novas relações entre professor e aluno que contribuam e encaminhem modificações das práticas avaliativas. Contrariando, entretanto esse princípio necessário, existe uma realidade no modelo educacional público onde os docentes continuam a agir como pontos de transmissão de conhecimentos e classificando e selecionando os resultados dos seus discentes.

As dificuldades na execução dessa nova visão de ensino-aprendizagem-avaliação e a necessidade real de que comece a produzir consequências benéficas, na existência de uma composição entre professor/aluno dentro de uma relação dialética e dialógica é fator 
preponderante na discursão de vários autores. Com base nos aspectos supracitados esse estudo aborda o tema avaliação contínua da aprendizagem como indicador da qualidade educacional.

Desta forma, o objetivo geral da pesquisa consiste em analisar a eficácia dos critérios da avaliação contínua da aprendizagem como indicador da qualidade educacional em um curso de graduação presencial em uma faculdade da rede pública estadual.

\title{
Avaliação: Referencial Histórico
}

Sob a ótica de Sant'Anna (1998, p.29-30) avaliação é:

\begin{abstract}
Um processo pelo qual se procura identificar, aferir, investigar e analisar as modificações do comportamento e rendimento do aluno, do educador, do sistema, confirmando se a construção do conhecimento se processou, seja este teórico (mental) ou prático.
\end{abstract}

O processo de avaliação é objeto de pesquisa latente, onde diversos pesquisadores buscam e querem melhorar a qualidade educacional de nosso país. Esse levantamento metodológico de cunho revisional bibliográfico objetiva-se em dar suporte teórico ao estudo.

A temática avaliação é originaria da escola modernista, onde existia a exigência prática de aplicação de provas e exames [...] (LUCKESI, 1995).

No século XVI a pedagogia jesuítica, mesmo tendo como norte a imposição e o rigor de procedimentos para a busca de uma eficiência avaliativa era caracterizada por sessões solenes através da formação de bancas de exames onde existia até a comunicação publica dos resultados obtidos pelos estudantes. No século XVII a pedagogia comeniana, dava atenção ao professor e as suas ações em sala de aula o tornando o centro de interesse da educação, porem, não deixaram de lado a utilização dos exames como forma avaliativa e de estímulo ao trabalho intelectual da aprendizagem. Segundo Luckesi (1995), destas duas pedagogias, surge o que hoje chamamos de Pedagogia Tradicional.

Com a ascensão da classe burguesa pautada na centralização e hierarquização do poder, nota-se que o modelo politico de sociedade passa a ser regido por exclusão e desta forma tanto a pedagogia jesuítica (século XVI), quanto à pedagógica comeniana (século XVII), segue essa mesma linha tendo o professor em sala de aula no centro do poder tomando as decisões no 
momento avaliativo como a aplicação de exames que buscam a aprovação ou a reprovação (exclusão) dos alunos (LUCKESI, 1995).

Já o termo avalição da aprendizagem é mais recente tem sua data de aparição ou surgimento em 1930, e é atribuído a Ralph Tyler, educador norte americano que se dedicou à questão de um ensino que fosse eficiente. O período compreendido entre 1930 e 1945 ficou intitulado como período "tyleriano" da avaliação da aprendizagem por pesquisadores da área (SAKAMOTO \& VERÁSTEGUI, 2008).

O modelo avaliativo da aprendizagem é baseado na fundamentação da identificação de potenciais, porem o modo operante ainda consiste na aplicação de provas e etc. Mesmo que vários docentes acreditem que o processo avaliativo é a engrenagem para a eficiência do ensino.

\section{O que é Avaliação Contínua da Aprendizagem?}

A maioria dos professores que lecionam no ensino superior não tiveram sua formação voltada para a docência, a não ser os que se formaram nas licenciaturas existentes, assim o professor dos dias atuais deve deixar de ser um acumulador de informações e deve preparar-se profissionalmente voltando-se à prática e a mediação pedagógica.

Masetto (2003, p.146), sugere que "devemos modificar as aulas, utilizando novas tecnologias, selecionando conteúdos significativos, desenvolvendo um relacionamento adulto com a turma colocando em prática a mediação pedagógica".

Qualquer que seja o processo avaliativo, o mesmo deve ser planejado, Masetto (2003), nos aponta exemplos:

Devemos em primeiro lugar quantificarmos as atividades (provas, trabalhos e etc.), aplicadas em períodos estabelecidos e daí chegarmos a uma pontuação conceitual. É preciso fazer a desvinculação do aluno da nota, contudo, é difícil nessa forma exemplificada;

- "Em segundo lugar devemos criar organização mediante a disciplina a transacionando em trabalhos por unidades. As atividades e as formas de avaliação devem ser acertadas com os discentes. Há necessidade de descrição e comentário por parte do docente aos seus discentes. Quando os objetivos não forem atingidos devese retomar as ações melhorativas criando-se novas oportunidades para o aprendizado. Ao termino, busca-se a nota que represente o aprendizado". 
Hadji (2001), afirma em seus escritos que um modelo avaliativo deve consagrar a regulação das aprendizagens, e ser capaz de criar orientação ao discente para que ele possa situar suas dificuldades, analisando-as e descobrindo-as, para lhe permitir progredir em sua vida. Sendo assim, o aluno ao ingressar no ensino superior já esta acostumado a pratica tradicional de avaliação centrada na obtenção de notas para possibilitar sua consequente aprovação na disciplina e posteriormente no curso.

Para Luckesi (1995), a avaliação deve ser uma atividade bem definida que se põe a favor da competência de todos, que tem a função de qualificação e não classificação.

Hoffmann (1999) discute os mitos da avaliação e propõe uma avaliação mediadora como possibilidade de acompanhamento contínuo e gradativo da aprendizagem do aluno.

Conforme a autora a avaliação contínua da aprendizagem nada mais é do que um tipo de avaliação que ocorre durante o processo de instrução do aluno e fornece informações ao professor para que o mesmo identifique e conserte as suas falhas e as falhas dos alunos, além de permitir a modificação da instrução dada caso a mesma seja a ideal para o atendimento individual das demandas discentes. Contudo os professores não devem só dar a aula e aplicar testes e provas, e sim criar ou modificar a forma de dar essas aulas e a aplicação destes testes e provas de forma a despertar nos alunos seus potenciais intrínsecos.

Para que isso seja modificado segundo Masetto (2003), será necessário que os professores estejam conscientes de quais competências, habilidades e atitudes devem ser avaliadas e desta forma acompanhar o desenvolvimento do aluno.

\section{Processo de Avaliação da Aprendizagem no Ensino Superior}

O ensino fundamental, o ensino médio, e o ensino superior no Brasil seguem a mesma temática no que diz respeito à questão avaliação, todos os três eixos educacionais são regidos por métodos que buscam a quantificação desses resultados por meio de notas atribuídas, assim sendo, não desenvolvem nem estimulam o potencial individual e coletivo dos alunos.

O ensino superior tem sido marcado por uma forma avaliativa ainda arcaica concentrada apenas no tirar notas que sejam suficientes para ser aprovados nas disciplinas e consequentemente na média final, que a depender da instituição pode variar entre $(6,0)$, e $(7,0)$. 
Para Masetto (2003, p. 147), o processo de avaliação deve "representar a aprendizagem tanto de alunos como professores. Caso contrário os alunos não terão interesse em aprender e sim de "tirar" a nota".

Contudo a LDB9394/1996, (Lei de Diretrizes e Base da Educação Nacional), seção I, artigo 24, inciso V parte a, afirma já existir a: “[...] Avaliação contínua e cumulativa do desempenho do aluno, com prevalência dos aspectos qualitativos sobre os quantitativos [...]". (BRASIL, 1996, p.10).

Desta maneira entende-se que mesmo ainda não existindo a prática sistêmica da avalição contínua da aprendizagem, a mesma já esta prevista e regulamentada na LDB9394/1996, faltando apenas politicas pedagógicas, mas incisivas para sua plena utilização ou mesclagem com o sistema já existente.

\section{Breve Análise sobre os tipos de Avaliações e Funções das Mesmas}

Existem vários tipos de avaliações e cada uma delas possui suas funções. Para Gardner (1998 apud SOUZA, 2002, p.36), “cada abordagem de avaliação é apropriada para uma circunstância específica".

A literatura pedagógica fala dos tipos de avaliação e as classifica da seguinte forma: avaliação formativa, avaliação diagnóstica, avaliação somativa, a avaliação cumulativa e a avaliação institucional.

Santos (2005, p.23), diz que a avaliação formativa:

Tem o propósito fundamental de verificar se o aluno está conseguindo dominar gradativamente os objetivos previstos, expressos sob a forma de conhecimentos, habilidades e atitudes (...), permitindo alterações ao longo do curso (...), função do controle da qualidade do trabalho escolar.

Pressupõe-se que esse tipo de avaliação, permita alterações no decorrer do processo do curso ou disciplina quando é possível.

Na visão de Allal \& Cardinet (1986, p.14) a avaliação formativa é a que:

[...] visa orientar o aluno quanto ao trabalho escolar, procurando localizar as suas dificuldades para o ajudar a descobrir os processos que lhe permitirão progredir na 
sua aprendizagem. A avaliação formativa opõe-se à avaliação somativa que constitui um balanço parcial ou total de um conjunto de aprendizagens [...].

Essa forma de avaliação busca orientar o aluno o ajudando na localização de suas dificuldades, tendo como atividade fim a descoberta de processos para sua progressão no ensino/aprendizagem ao invés de só quantificá-lo, através de uma nota.

Gil (2006, p.247), informa que a avaliação diagnóstica.

Constitui-se num levantamento das capacidades dos estudantes em relação aos conteúdos a serem abordados, com essa avaliação, busca-se identificar as aptidões iniciais, necessidades e interesses dos estudantes com vistas a determinar os conteúdos e as estratégias de ensino mais adequadas.

Segundo o ponto de vista de Kraemer (2006), a avaliação diagnóstica é baseada na aprendizagem de investigação, através dos conteúdos disponíveis para servirem de base criativa e diagnóstica de possíveis dificuldades futuras, possibilitando a resolução de situações atuais.

Ao analisar a avaliação diagnóstica entende-se que a mesma busca levantar, ou seja, fazer um diagnostico acerca de cada aluno referente à suas aptidões que são diferenciadas, buscando a criação de estratégias para melhor direcionar os mesmos.

Wachowicz \& Romanowski (2003, p.124-125) destacam que a avaliação somativa:

\begin{abstract}
Manifesta-se nas propostas de abordagem tradicional, em que a condução do ensino está centrada no professor, baseia-se na verificação do desempenho dos alunos perante os objetivos de ensino estabelecidos no planejamento. Para examinar os resultados obtidos, são utilizados teste e provas, verificando quais objetivos foram atingidos considerando-se o padrão de aprendizagem desejável e, principalmente, fazendo o registro quantitativo do percentual deles.
\end{abstract}

A avaliação somativa faz a verificação de desempenho dos alunos após a aplicação de testes e provas, onde é analisado se os objetivos foram alcançados depois das correções, esse tipo de avaliação tem a função classificatória e por fim os resultados são quantificados através de notas que foram atribuídas a estes testes e provas.

Santos (2005, p.23), qualifica a avaliação somativa, como sendo aquela em que:

O aluno é promovido de acordo com o aproveitamento alcançado nos componentes curriculares estudados. É utilizada com o propósito de atribuir uma nota ou um conceito para fins de promoção e tem função classificatória (...). Serve para julgar e classificar o aluno segundo seu aproveitamento ao final de uma unidade, semestre, série ou curso. 
É o tipo de avaliação mais utilizado pelos professores, pois o mesmo acaba sendo o método mais fácil de avaliação.

$\mathrm{O}$ autor ainda informa que existem mais dois tipos de avaliações, são elas: A avaliação cumulativa que é "aquela que permite como o nome já diz a acumulação de dados coletados através de um acompanhamento sistêmico relacionado à aprendizagem" (SANTOS, 2005, p. 24). E a avaliação institucional que "possibilita a captação de diversas informações sobre o objeto alvo da avaliação com o intuito de se comparar e propor melhorias referentes a esse objeto" (SANTOS, 2005, p.25).

A forma progressista como é abordada a avaliação é descrita como: sistêmica, contínua, processual e transformadora. Funde-se como uma troca dialogada entre docentes e discentes (BEHRENS, 2005).

\title{
Critérios de Eficácia da Avaliativa da Aprendizagem
}

Hoffmann (1999, p.137), considera urgente e essencial o repensar sobre a avaliação da aprendizagem na Universidade, pela sua condição de formadora de professores que irão atuar nas escolas. Ainda nessa linha de pensamento, Vasconcellos (2000, p.84), lembra que:

\begin{abstract}
As experiências que os futuros educadores têm no seu processo de formação são decisivas para suas posturas posteriores, na prática da sala de aula. Há, portanto, necessidade que esses educadores tenham já na sua formação uma nova prática em termos de avaliação. Apesar de teoricamente não se aceitar mais o 'faça o que eu digo, mas não faça o que eu faço', no cotidiano dos cursos de formação é isto que se observa também em relação à avaliação, ou seja, os futuros professores recebem uma série de conceitos bonitos sobre como deve ser a avaliação de seus alunos, mas é avaliado no esquema bem tradicional. Assim, quem trabalha com a formação acadêmica dos novos professores tem também um compromisso de mudar a prática de avaliação dos mesmos.
\end{abstract}

Os dois autores afirmam que os futuros concluintes de graduação, possíveis professores, irão repassar aos seus futuros alunos, essa mesma forma avaliativa a qual os mesmos foram submetidos.

Para Perrenoud (1999), principio avaliativo escolar permeia a um modelo tradicional e outro emergente, um conduz a seleção e outro conduz a aprendizagem. Desta forma percebese que deve existir de forma emergencial uma nova reestruturação de cunho eficaz em relação 
aos critérios da avaliação, fazendo com que as próximas gerações de docentes adotem essa nova pratica de avaliação contínua de aprendizagem.

\title{
Estrutura adequada para a Avaliação Contínua da Aprendizagem
}

"O sentido fundamental da ação avaliativa é o movimento, a transformação, o que implica num processo de interação educador e educando, num engajamento" (HOFFMANN, 1999, p.110).

A avaliação nesse sentido passar a ser uma forma direta de interação entre professor e aluno, deixando de lado a mera aplicação de provas e testes para a simples quantificação de resultados para uma classificação.

Perrenoud (1999, p.10), diz: “falar de avaliação formativa não é mais um apanágio de alguns marcianos".

\begin{abstract}
(...) nenhuma inovação pedagógica maior pode ignorar o sistema de avaliação ou esperar contorná-lo. (...) é necessário em qualquer projeto de reforma, em qualquer estratégia de inovação, levar em conta o sistema e as práticas de avaliação, integrá-los à reflexão e modificá-los para permitir a mudança. (...) a avaliação tradicional é uma amarra importante que impede ou atrasa todo tipo de outras mudanças. Soltá-la é, portanto, abrir a porta a outras inovações. (PERRENOUD, 1999, p.75 e p.76).
\end{abstract}

O autor informa que não se podem esquecer as antigas práticas de avaliação, ou seja, ambas devem ser integradas, contudo o novo modelo pedagógico voltado a mudanças é necessário.

Hoffman (1996) também sugere alguns princípios norteadores para uma avaliação formativa:

a) Criar momentos para os discentes expressarem suas idéias;

b) Possibilitar discussão entre os discentes sobre situações problemas;

c) Usar a linguagem informativa ao invés de certo ou errado e pontuação tradicional;

d) Transformar os registros avaliativos em anotações de acompanhamento do processo de construção de conhecimentos.

Para uma boa avaliação contínua da aprendizagem (avaliação formativa), a mesma deverá passar pela ação estruturada e adequada durante o processo de instrução para o melhor e maior conhecimento em relação ao aluno, a constatação do que se esta aprendendo por parte 
do aluno/professor, uma melhor adequação do processo de ensino referente aos alunos e em relação às dificuldades e um julgamento global no processo de ensino/aprendizagem no final de cada unidade, analisando o sucesso alcançado.

\section{Dificuldades na Utilização da Avaliação Contínua da Aprendizagem}

A avaliação contínua da aprendizagem é uma excelente ferramenta pedagógica, a mesma cria espaço personalizado e estimula o ensino/aprendizagem do discente. Ou seja:

A prática avaliativa deve ser capaz de ir além de avaliar a aprendizagem, mas entender o valor individual de cada aluno, propiciando o seu crescimento como indivíduo e como integrante de uma sociedade. E que acima de tudo, seja uma avaliação envolvida com uma prática pedagógica real, inovadora, não excludente e muito amorosa. (LUCKESI, 1995 p.37).

Contudo a avaliação contínua apresenta algumas dificuldades para sua utilização:

Primeiro ela funciona melhor em salas com poucos alunos, exigindo uma adequação a nossa realidade educacional, que é de salas superlotadas com um quantitativo de alunos muitas vezes superior a 50 alunos para um professor. Tal realidade impossibilita que o professor conheça cada um de seus alunos, além de conhecer seus gostos e expectativas, desta maneira causando uma ineficiência na monitoria junto aos alunos e desfavorecendo um resultado com justiça no que se refere ao processo avaliativo.

A avaliação da aprendizagem deverá ser assumida como um instrumento de compreensão do estágio de aprendizagem em que se encontra o aluno, tendo em vista tomar decisões suficientes e satisfatórias para que se possa avançar no seu processo de aprendizagem (DANIELS, 1994 apud VYGOTSKY, 1997 p.11).

Segundo, para o alcance do momento do saber, a avalição deverá fundamentar-se em 4 pontos:

a) Continuidade: Avaliação em todo o processo;

b) Compatibilidade: Avaliação em conformidade com os objetivos definidos;

c) Amplitude: Avaliação presente em todas as perspectivas do processo educacional;

d) Diversidade de forma: Avaliar usando várias técnicas possíveis. 
Não ocorrendo, o processo de diagnóstico será prejudicado por falta de critério ou por falta de conhecimento pelo docente.

E em terceiro, seria de extrema importância mudar uma cultura enraizada no Brasil, onde existe uma necessidade de quantificar o desempenho em notas ao invés de compreender o diagnóstico exposto em um relatório.

\begin{abstract}
Avaliar se refere a qualquer processo por meio do qual algumas ou várias características de um aluno/a, de um grupo de estudantes, de um ambiente educativo, de objetivos educativos, de materiais, professores/as, programas etc., recebem a atenção de quem avalia, analisam-se e valorizam-se suas características e condições em função de alguns critérios ou pontos de referencia para emitir um julgamento que seja relevante para educação. (STUFFLEBEAM, 1987 p.19).
\end{abstract}

\title{
Método Adotado
}

Quanto aos objetivos, a pesquisa a que se baseia este estudo é de natureza exploratória. Beuren (2004, p.81), afirma que a pesquisa exploratória é um estudo intermediário à explicativa, ou seja, não é tão preliminar como a primeira, nem tão aprofundada como a segunda".

A pesquisa caracterizou-se como bibliográfica, pois abordou e explicou um determinado tema a partir de alguns referenciais. De acordo Cervo e Bervian (1983, p.55), pesquisa bibliográfica é a pesquisa que: "explica um problema a partir de referenciais teóricos publicados em documentos. Pode ser realizada independentemente ou como parte da pesquisa descritiva [...]". Assim neste projeto foi introduzida uma ação metodológica através do levantamento de cunho bibliográfico em artigos, projetos, livros e textos on-line.

O projeto baseou-se, ainda, no contexto e orientações de Luckesi (1995), para o desenvolvimento "estudo" para a compreensão e interpretação dos fenômenos educacionais e de critérios avaliativos utilizados.

Para Gil (1999, p.42), a pesquisa é um "processo formal e sistemático de desenvolvimento do método científico. O objetivo fundamental da pesquisa é descobrir respostas para problemas mediante o emprego de procedimentos científicos".

Até chegarmos à implementação deste projeto, houve a necessidade de embasamento teórico envolvendo autores como Luckesi (1995), Masetto (2003), Hoffmann (1999), Chueriri 
(2008), Pacheco (1995), Perrenoud (1999), Santos (2005), Stufflebeam (1987), e outros, assim como Lei de Diretrizes e Base da Educação Nacional, o Projeto Político Pedagógico e o Regimento de uma faculdade pública.

\section{Considerações Finais}

Com o objetivo de analisar a eficácia dos critérios da avaliação contínua da aprendizagem como indicador da qualidade educacional em um curso de graduação presencial em uma faculdade da rede pública estadual. Houve a necessidade de identificação do que seria à avaliação da aprendizagem, na visão e análise de autores conceituados o que possibilitou a descoberta de um processo complexo, porém necessário para objetivação de ações imprescindíveis para a melhoria do aprendizado docente e discente.

Além da identificação, o estudo buscou examinar a eficácia dos critérios da avaliação contínua da aprendizagem. Dentro deste contexto, foi constatado que os atuais critérios são ineficazes, devendo os mesmos passarem por uma reestruturação, fazendo com que as novas gerações de docentes adotem a avaliação contínua de aprendizagem como norte nas salas de aula.

Após o exame da eficácia, foi investigada a estrutura de avaliação adequada para garantia dos objetivos para a qualidade educacional estabelecida. Sendo assim, o estudo, constatou que a atual estrutura praticada pelos ambientes educacionais de ensino superior no Brasil, está fora de harmonia, com os preceitos norteadores da avaliação contínua da aprendizagem. A estrutura atual preza pela aplicação de testes e provas, para a simples quantificação de resultados para uma classificação, porém a nova estrutura preza pela ação estruturada e adequada durante o processo de instrução do aluno, para o melhor e maior conhecimento em relação ao mesmo, dando maior ênfase em relação à solução das dificuldades individuais dos mesmos.

Foram também encontradas dificuldades na utilização da avaliação contínua como: Salas de aula cheias, muitas vezes com mais de 50 alunos, o que impossibilita o atendimento individualizado e personalizado aos alunos; falta de critérios técnicos delimitados de forma especifica para que o aluno seja estimulado a alcançar seu próprio saber, essa falta de critério 
se dá em parte pela falta de preparo do professor e em parte pela falta de conhecimento pelos alunos de fundamentos como (continuidade, compatibilidade, amplitude e diversidade de forma); e por fim seria necessária uma mudança drástica na cultura enraizada no Brasil, onde existe uma necessidade de quantificar o desempenho dos alunos em notas ao invés de compreender o diagnóstico exposto em um relatório.

O processo de inserção da avaliação contínua da aprendizagem no ensino superior publico no Brasil, ainda esta no inicio. Desta forma o presente estudo não pretende ser conclusivo, todavia sugere-se para trabalhos futuros, pesquisar qual a participação efetiva dos Governos (federal, estadual e municipal), na inserção da avaliação contínua da aprendizagem como novo molde mestre na educação brasileira.

\section{Referências}

ALLAL, L.; CARDINET, J.; PERRENOUD, P. A avaliação formativa num ensino diferenciado. Coimbra: Livraria Almedina, 1986.

BEHRENS, M. A. O paradigma emergente e a prática pedagógica. Petrópolis, RJ: Vozes, 2005.

BEUREN, Ilse Maria. Como elaborar trabalhos monográficos em Contabilidade: teoria e prática. $2^{\circ}$ ed. São Paulo: Atlas, 2004.

BRASIL. Lei $\mathbf{n}^{0} 9.394$ de 20 de dezembro de 1996. Estabelece as diretrizes e bases da educação nacional. Disponível em: http://portal.mec.gov.br/arquivos/pdf/ldb.pdf. Acesso em: 25 abr. 2015.

CERVO, A. L.; BERVIAN, P. A. Metodologia científica: para uso dos estudantes universitários. São Paulo: McGraw-Hill do Brasil, 1983.

CHUERIRI, S. F. Concepções sobre avaliação escolar. Estudos em Avaliação Educacional, v. 19, n. 39 , p. 49-64, jan./abr. 2008

GIL. A. C. Métodos e Técnicas de Pesquisa Social. 5.ed. São Paulo: Atlas, 1999. p.42.

GIL, A. C. Didática do ensino superior. São Paulo: Atlas, 2006. p. 247.

KRAEMER, M. E. P. Avaliação da aprendizagem como construção do saber. Revista eletrônica: Educación Superior. Investigaciones y Debates, 2006. Disponível em: http//integral.objectis.net/avaliarsaberes. Acesso em: 24 abr. 2015.

HADJI, C. Avaliação desmistificada. Porto Alegre. RS: Artmed, 2001.

HOFFMANN, J. M. L. Avaliação mediadora: uma prática em construção da pré-escola à universidade. 15.ed. Porto Alegre: Mediação, 1999. 
LUCKESI, C. C. Avaliação da aprendizagem escolar. São Paulo: Cortez, 1995.

MASETTO, M. T. Competência pedagógica do professor universitário. São Paulo: Summus, 2003.

PACHECO, J. A. A Avaliação dos alunos na perspectiva da reforma 2. ed. Porto, 1995 a.

PERRENOUD, P. Avaliação: da excelência à regulação das aprendizagens: entre duas lógicas. Trad. Patrícia Chittoni Ramos. Porto Alegre: Artes Médicas Sul, 1999. p.10.

ROMANOWSKI, J. P.; WACHOWICZ, L. A. Processos de ensinagem na universidade: In: ANASTASIOU, Lea das Graças Camargo. Pressupostos para as estratégias de trabalho em aula. Santa Catarina: UNIVILLE, 2003. p.124 -125.

SAKAMOTO, B. A. M.; VERÁSTEGUI, R. de L. A. Por uma Mudança na Avaliação de Exclusão. Educere et Educare: Revista de Educação. v. 3, n. 6, p.139-151, jul./dez. 2008.

SANT'ANNA, I. M. Por que avaliar? Como avaliar?: Critérios e instrumentos. Petrópolis: Vozes, 1998.

SANTOS, C. R. Avaliação educacional: um olhar reflexivo sobre sua prática. São Paulo: Avercamp, 2005.

SOUZA, A. M. C de. Avaliação institucional para a melhoria do ensino e da aprendizagem. In: FELTRAN, R. C. S (org.) Avaliação na educação superior. Campinas: Papirus, 2002.

STUFFLEBEAM, D. EvoluaciónSistemática. Barcelona: Paidós-MEC, 1987.

TYLER, R. Princípios Básicos de Currículo e Ensino. Porto Alegre: Globo, 1975.

UNEB. Regimento geral da UNEB. Disponível em: http://www.uneb.br/files/2009/10/REGIMENTOGERAL-DA-UNEB-2012.pdf. Acesso em: 26 abr. 2015.

VASCONCELLOS, C. dos S. Avaliação da Aprendizagem: práticas de mudança. São Paulo: Libertad, 2000.

VYGOTSKY, L. S. Vygotsky em Foco: pressupostos e desdobramentos. 3.ed. Campinas, SP: Papirus, 1997.

\section{Como citar este artigo (Formato ABNT):}

FONSECA, Ubaldo de Jesus; LOPES, Mário Marcos. Avaliação Contínua da Aprendizagem como Indicador da Qualidade Educacional. Id on Line Revista Multidisciplinar e de Psicologia, 2018, vol.12, n.41, p.124-138. ISSN: 1981-1179.

Recebido: 31.05 .2018

Aceito: 11.06 .2018 